\section{EMBRYRIDDLE \\ Aeronautical University}

SCHOLARLY COMMONS
International Journal of Aviation, Aeronautics, and Aerospace

\title{
Towards a hybrid comfortable passenger cabin interior for the flying $\mathrm{V}$ aircraft
}

\author{
Peter Vink \\ Delft University of Technology, p.vink@tudelft.nl \\ Thomas Rotte \\ Delft University of Technology, thomasrotte@hotmail.com \\ Shabila Anjani \\ Delft University of Technology, S.Anjani@tudelft.nl \\ Chiara Percuoco \\ University of Naples Federico II, chiara.percuoco@unina.it \\ Roelof Vos \\ Delft University of Technology, R.vos@tudelft.nl
}

Follow this and additional works at: https://commons.erau.edu/ijaaa

Part of the Aerospace Engineering Commons, Other Physiology Commons, and the Social and Behavioral Sciences Commons

\section{Scholarly Commons Citation}

Vink, P., Rotte, T., Anjani, S., Percuoco, C., \& Vos, R. (2020). Towards a hybrid comfortable passenger cabin interior for the flying $\mathrm{V}$ aircraft. International Journal of Aviation, Aeronautics, and Aerospace, 7(1).

https://doi.org/10.15394/ijaaa.2020.1431

This Special Purpose Document is brought to you for free and open access by the Journals at Scholarly Commons. It has been accepted for inclusion in International Journal of Aviation, Aeronautics, and Aerospace by an authorized administrator of Scholarly Commons. For more information, please contact commons@erau.edu. 
Towards a hybrid comfortable passenger cabin interior for the flying $\mathrm{V}$ aircraft Cover Page Footnote

Acknowledgement The authors want to thank KLM for sponsoring and supporting the project. 
A new type of long-haul aircraft, 'the Flying $\mathrm{V}$ ' is in development, which consumes less energy by its form (https://www.tudelft.nl/lr/flying-v/). Air transport currently accounts for around $2 \%$ of the 36 billion tonnes of $\mathrm{CO}_{2}$ generated annually by human activities (https://www.cleansky.eu/benefits), showing the need to develop a more fuel-efficient aircraft. This Flying V is originally an idea of TU Berlin student Justus Benad during his thesis project at Airbus Hamburg (https://www.tudelft.nl/lr/flying-v/). In the Flying V, the passenger cabin, cargo hold and fuel tanks are integrated in its wing structure. The Flying V carries about the same number of passengers as the Airbus A350, which is the benchmark for this new airplane. The Flying V is smaller than the A350 and has less wetted surface area compared to the available amount of volume. The result is less resistance, which causes less fuel need for the same distance. At the moment the Flying $\mathrm{V}$ is in development for using traditional kerosene engines, but also alternative ways of propulsion will be studied like hydrogen or e-kerosene, but this is not the purpose of this study.

The Flying $\mathrm{V}$ does not consist of a traditionally configured circular fuselage with a set of wings, but rather integrates the cabin into the wing itself. The resulting cabin has a flat oval cross section which would deform to circular when pressurized at high altitudes. In order to prevent this, a rectangular frame is positioned in the oval cabin (Vos, Geuskens, \& Hoogreef, 2012). In fact, the inside space of the rectangular is the space where seats can be placed (6.00 $\mathrm{m} \mathrm{x}$ $2.15 \mathrm{~m})$. This shape asks for new interior concepts.

The development of new interior concepts is not only driven by the shape of the flying V but also by the passenger's comfort. Passenger comfort is clearly a key variable in research on user acceptance of transportation systems, and it is related to passenger's satisfaction and the willingness to fly again ( $\mathrm{Li}$, Chu, Gou, \& Wang, 2018). Anjani, Li, Vink, and Ruiter (2019), and Bouwens, Tsay, and Vink (2018) have shown the need to improve seating: seat comfort has been seen as a necessity rather than a luxury. According to a study conducted by Airbus, long-haul economy passengers take great care over seat comfort in long flights, and they are willing to pay more for this. In the study, $54 \%$ of economy passengers stated that seat comfort was essential, while $41 \%$ of the passengers stated that they were willing to pay more for better seat comfort (Atalık, Bakır, \& Akan, 2019). Kremser, Guenzkofer, Sedlmeier, Sabbah, and Bengler (2012) and Hiemstra-van Mastrigt (2015) demonstrated the need to change postures as a passenger. Furthermore, the possibility to change one's posture easily could lead to the effect that passengers do not sit too static on an airplane and perform different activities. Sleeping is one of the common activities during the long haul flight: Bouwens, Hiemstra-van Mastrigt, and Vink (2017) showed that almost $80 \%$ of the passengers sleep, but due to the upright posture the comfort is rated low (4.3 at a scale of 1-10); Torkashvand (2019) showed that on long haul flights the lowest satisfaction was found for the activity 'sleeping' (the score is 2.75 on a scale $1-5$, where from $1=$ "not at all satisfied" and 5= "extremely satisfied"). So, there is also a need to improve the passenger experience by creating new interior concepts that can 
answer to the different passenger needs. Therefore, in this paper an attempt is made to develop aircraft interior concepts that fit in the Flying $\mathrm{V}$ and could improve the passenger experience.

A requirement was that, for a given floor area, the interior should have space for 315 passengers comparable to the Airbus A350. An additional requirement was that the weight of the new interior elements should be lower than the current interior elements to reduce energy consumption even further.

\section{Method}

To develop concepts for the interior of the Flying V, 80 students were asked to come up with ideas in groups of 3-4 (22 groups). Before generating ideas, the students were informed about the Flying V concept and its oval cabin (including dimensions). The number of passengers that had to fit in the airplane was explained as well. Also, improvement possibilities based on current surveys among passengers were mentioned, such as the need for more space, more variation of posture, the need for sleeping comfortably, that $28 \%$ of the passengers travel in groups (Homburg, 2017), that talking to each could distract of discomfort (Hiemstra-van Mastrigt, 2015), and food could distract from discomfort (Hiemstra-van Mastrigt, 2015; Yao \& Vink, 2019).

The 22 groups of students were also sensitized and received a lecture on aircraft interiors in a Boeing 737 to experience aircraft interiors again. Each group presented one or more ideas and a jury of experts from KLM (an airline), Safran (a company making airplane interior parts), Airbus, and TU-Delft selected the best 4 ideas. The groups that had the ideas did receive a studentassistant appointment. In that appointment, they were asked to further elaborate the concept and make it into a drawing which can be made.

Simultaneously, the researchers developed a 1:1 mock-up (see Figure 1) and a stand builder was asked to make the mock-up frame and a part of the interior. A seat manufacturer (Rebel aero) was asked to develop seats that were positioned staggered as was suggested in the ideas of the students. Also, a design language was developed to create unity in the interior design. The method of generative design was chosen here as it could contribute to less weight and at the same time have recognisable design elements. The four concepts in the mock-up were shown to the public (potential passengers) at the fair where KLM 100 years was celebrated during 9 days. 

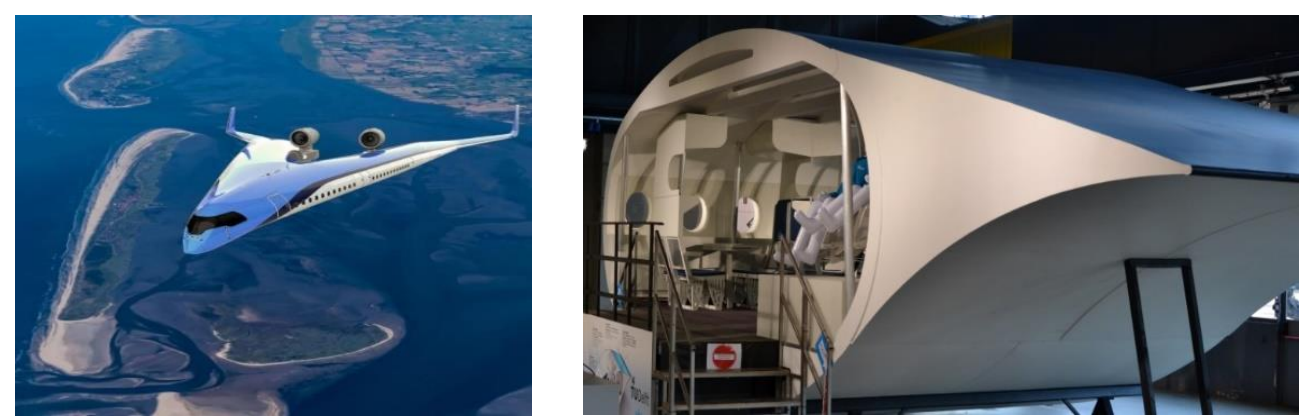

Figure 1. The Flying V (left) and the mock-up of the interior of the Flying V (right).

At the beginning of the visit, two tickets were provided to each visitor to allow him/her to express his/her preference on the concepts presented in the mock-up. The preferences are asked under two travel conditions: when he/she travels alone or when he/she travels in a group (at least 2). The visitors provided their preferences at the end of the visit, inserting his/her preference in one of the four boxes that represented the four interior concepts shown in the mock-up.

Additionally, the concepts were discussed with most of these visitors. In the discussion it was explained that during a flight, passengers could book for instance a bed for the first half and a staggered seat for the second half of the flight, suggesting a new way of booking the flight.

\section{Results}

The four chosen concepts were the chaise longue (see Figure 2), the group space (see Figure 3), the beds (see Figure 4), and the 'staggered' seats for the middle of the Flying V interior (see Figure 5).
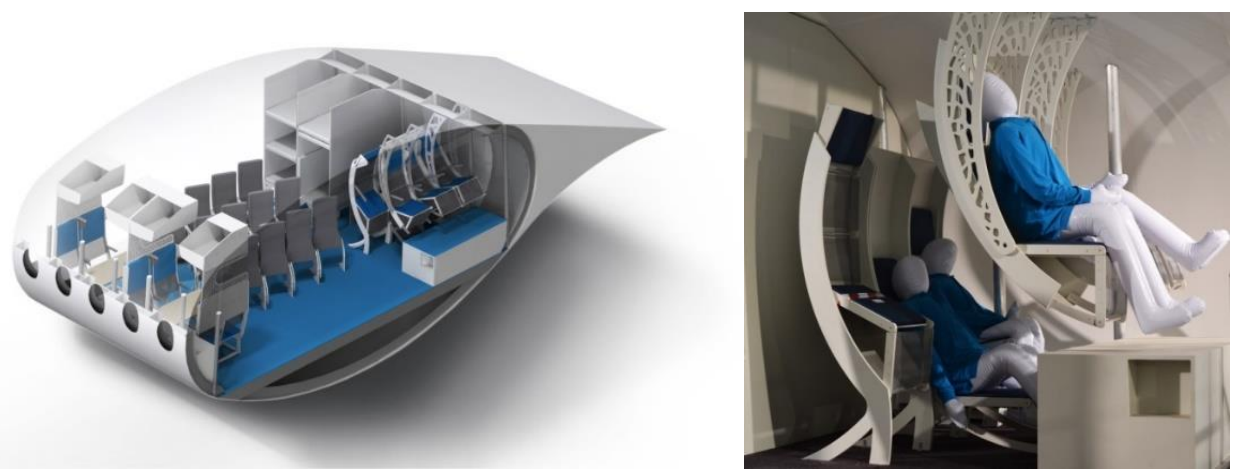

Figure. 2. A schematic overview of the mock-up (left) and one of the concepts for the interior of the Flying V: the chaise longue (right). 


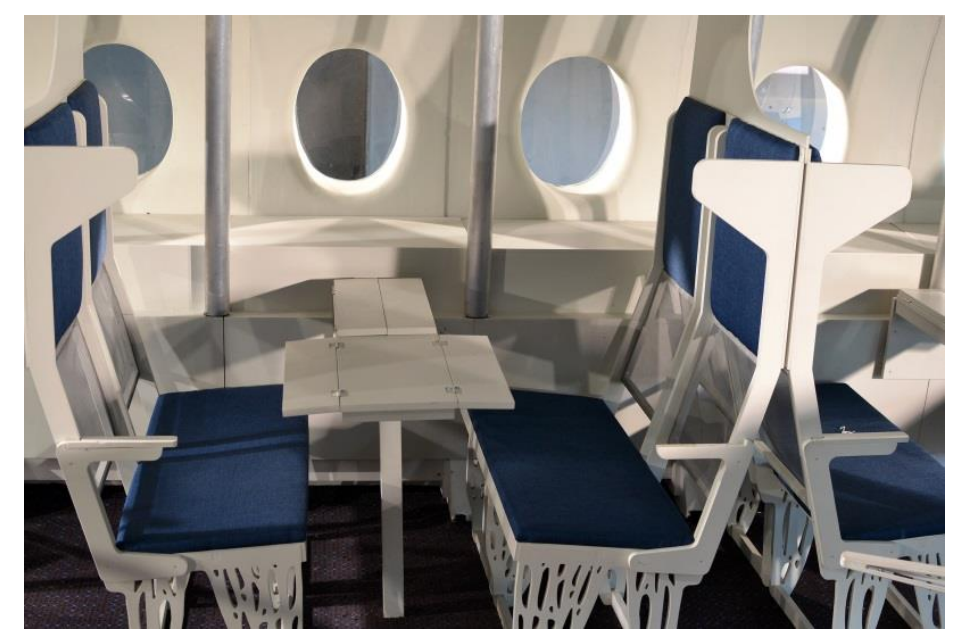

Figure 3. One of the concepts for the interior of the Flying V: the group space.

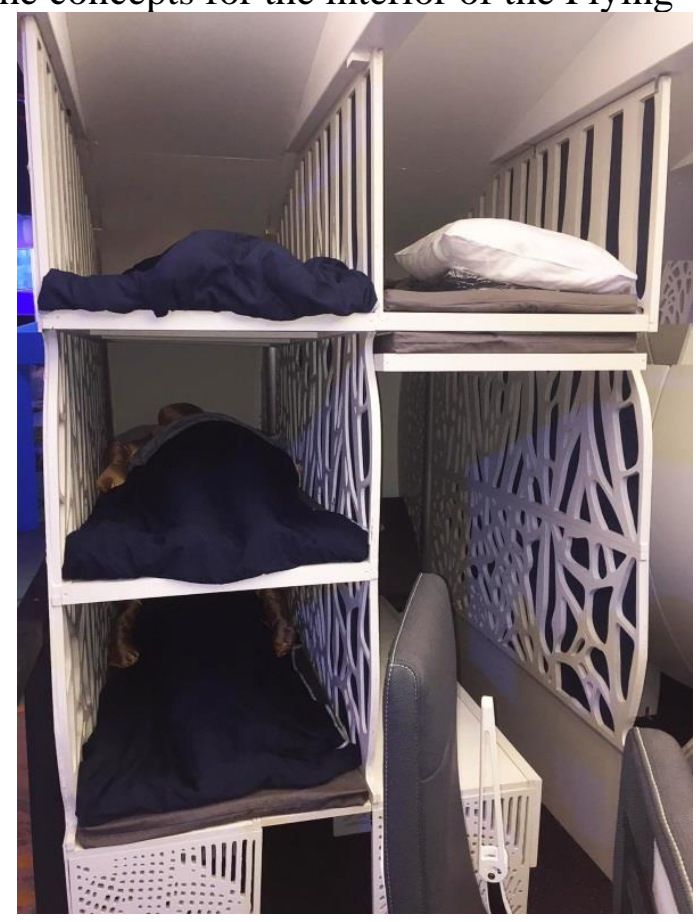

Figure 4. One of the concepts for the interior of the Flying V: the beds. 


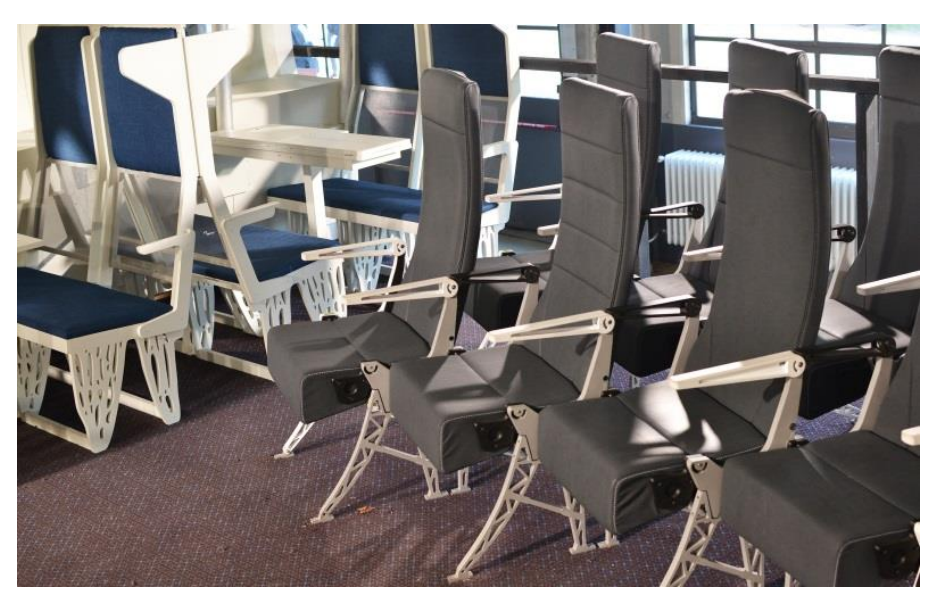

Figure 5. One of the concepts for the interior of the Flying V: the staggered middle seats.

In the chaise longue concept, it is possible to change the position of the human body. There is a more upright position for eating and working with the laptop and a more reclined position for relaxing and sleeping. It uses the available space in the aircraft by hanging the top seats from the ceiling. As the cabin is oval, and the ceiling consists of horizontal beams, mounting is possible. There is a rail in which the seat moves to different positions. Three seats are mounted to the floor and three to the ceiling. The ones mounted to the ceiling have a foot step to get into the seats. This way two rows of seats take up the same floor space of 64" ( $2 \times 32$ " pitch), but allow more variation of posture for the passengers. There are three positions: a position for passing each other during ingress and egress (most left seat in Figure 2) and the other two positions (upright and relaxed).

In the group space, two pairs of seats are position opposite to each other with a table in between. To allow ingress and egress a part of the table is made foldable. Also, between both seats a separation between the heads can be pulled out of the backrest at head level. This is to create some privacy when two groups of two are in the seats. The lower part of the backrest is a net, which stretches a bit and the form of the back rest is based on the curve described by Nijholt et al. (2016). These four seats (2x2) could take up less than 64" of space in the cabin's longitudinal direction, as it is assumed that the knees of two persons opposite to each other can touch each other as these persons are acquaintances. For the same reason, and because the group seats are designed as 2 -seaters, the total width could also be smaller than the total width of 2 separate seats. The additional space between the rectangular frame and the oval cabin wall provides more visual space, some shoulder space and the possibility to put some personal belongings.

In the concept beds, it is possible to sleep in a flat bed. The original rectangular frames to keep the oval cabin oval at high altitudes were positioned $50 \mathrm{~cm}$ from each other. However, as we wanted to have beds in between the rectangular frames, $70 \mathrm{~cm}$ would be better and a redesign was made of the frame structure in the oval cabin. The $70 \mathrm{~cm}$ frame distance makes it possible to 
position the beds between the frames and use the space in the posterior part of the wing. This way a $190 \mathrm{~cm}$ long bed only uses $140 \mathrm{~cm}$ of the length of the area within the rectangular frame. It is not allowed to lay flat during take-off and landing. Evacuation will take too much time. To prevent losing capacity in the number of passengers, a part of the bed area had to made transformable to a seat. The solution developed was to lift the middle bed up and let a part of the lower bed flip down from horizontal to vertical and to create for three persons a seat. In Figure 4, the left three beds are in a sleeping position and the right three beds in a sitting position.

The middle seats are placed in the direction of flying with a seat pitch (in the longitudinal cabin direction) of 32". These seats were 18 " wide, placed four abreast in a staggered position. As the wing has an angle of 26 degrees with respect to the direction of flying, the seats have an angle of 26 degrees with respect to the oval tube. To make ingress and egress possible the seat pan can be folded, a principle designed by Rebel Aero (see Figure 6). This also has the advantage that passengers can temporarily take another position on the folded seat. Another advantage of the staggered seats it that shoulders and the elbows at the armrests are not touching each other easily. By rotating the seats, the leg room was comparable to a 38 " pitch.

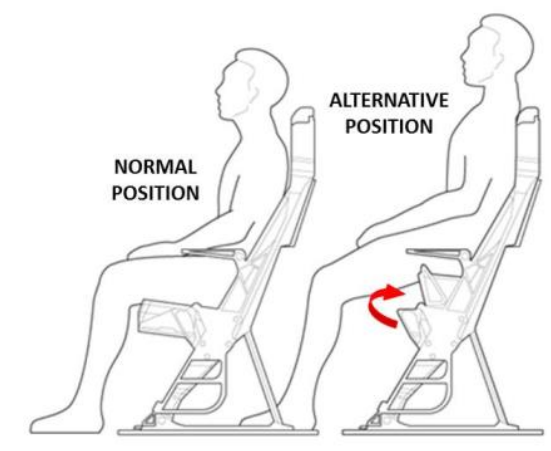

Figure 6. The principle of the folded aircraft seat developed by Rebel Aero.

\section{The Visitor Comments}

A total of 1692 visitors of the mock-up provided their preference for one the four concepts. The sample of visitors (potential passengers) was very heterogeneous. The majority were middle-aged, but also young visitors of 10 years old and elderly of more than 70 years old visited the booth. They had to give their preference when they fly alone and when they fly in a group of at least 2. In Figure 7, the preferences of the 1692 visitors of the Flying V are shown. It makes sense that there is a preference for the group seats when travelling in groups. However, it was a surprise that the chaise longue was the favourite for individual travelling and even for travelling in groups there were many votes for this seat. 

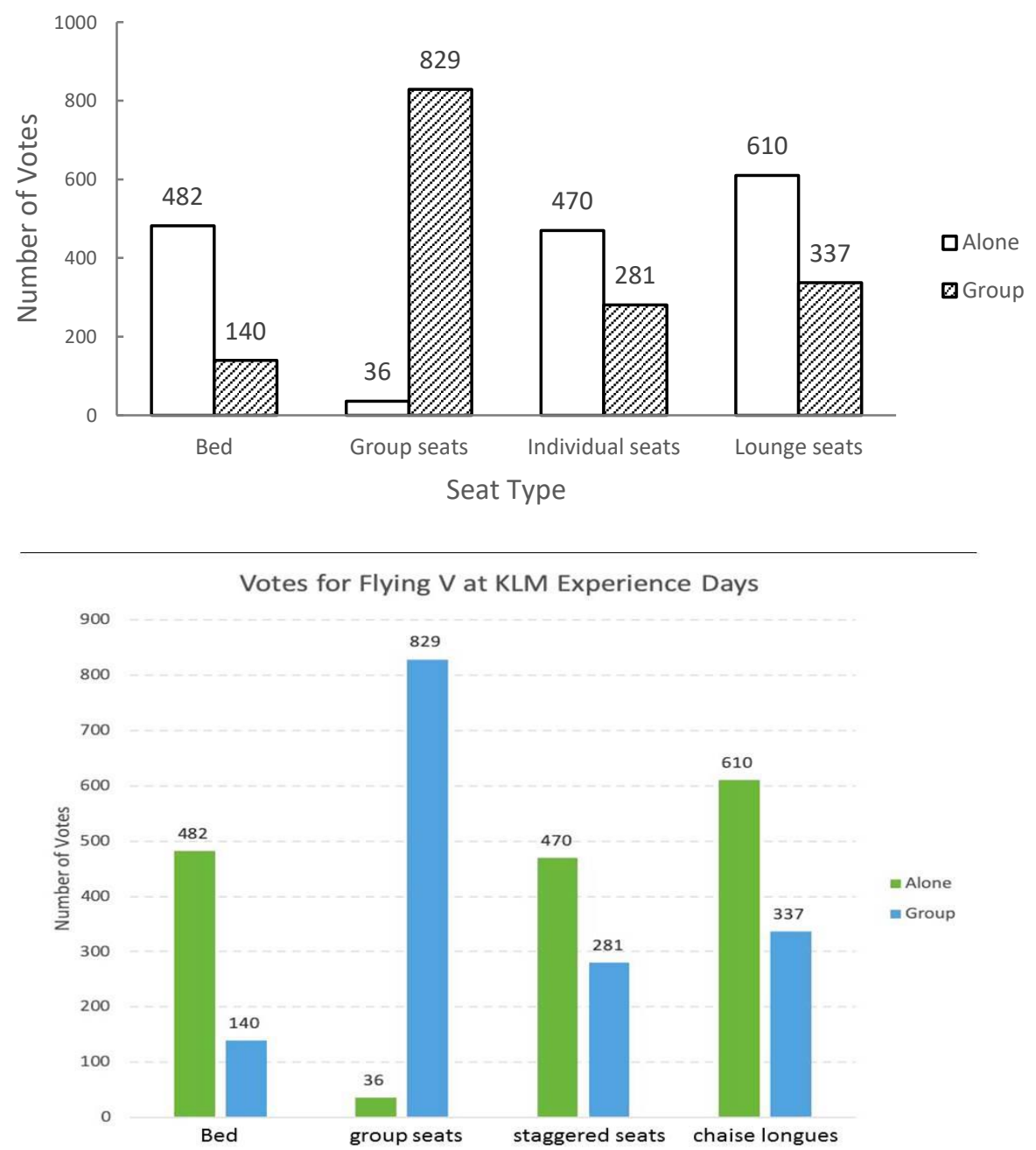

Figure 7. Votes of the 1692 visitors for the concept.

In the discussions the flight attendants mentioned that changing half way during the long-haul flight might be a problem. If everyone changes at the same time, it will be uneasy. Perhaps this should be regulated and be done in groups at different times.

The group space was seen as interesting and reminded the visitors of train seats. They did mention as well that 12 hours in this position is too much. Planners of an airline said that it might be true that on average $28 \%$ travel in groups, but less group spaces should be made in the airplane as there will be flights with only $10 \%$ groups and then these places will not be booked, which is unfavourable for an airline. So, preferably less than $28 \%$ should be group space.

The chaise longue was really appreciated as the human body position can be changed. Notably, the relax position was seen as a benefit. The demonstrated seat was not fully functional, which means that the visitors could only visually inspect the situation and not sit in it. Some visitors mentioned that 
it could be a claustrophobic experience when the lower person is sitting upright and the person above will recline.

The flat bed was also appreciated, as sleeping is really an issue now, but being in the bed for the full 12 hours is not preferred according to some visitors. Also eating in this position might be an issue. Perhaps also at eating time the taxi, take-off and landing position should be taken. Getting in and out of the bed and changing the sheets during the flight should be tested as well as there were some doubts about this by the visitors. A suggestion was made to give every passenger that will sleep his own sheet and cushion to give the passenger certainty on the hygiene. Especially, elderly getting in and out of the highest bed could be troublesome.

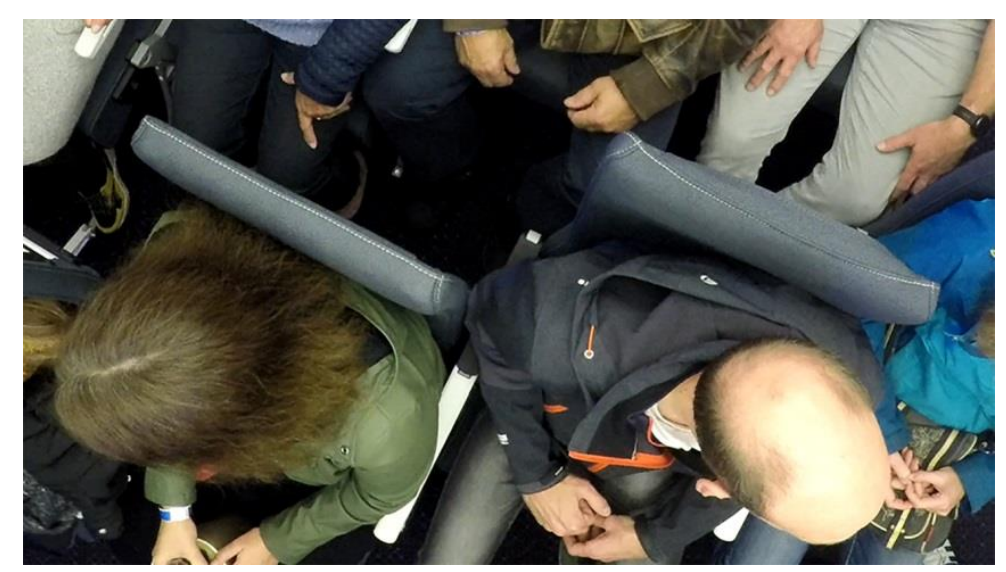

Figure 8. The staggered middle seats of Rebel Aero in the flying V showing that shoulders do not contact each other and elbows are at a different place on the armrest.

It was also clear that the staggered seats were appreciated above the conventional seat configuration, because of the shoulder space, armrest privacy and legroom. The shoulders do not touch each other (see Figure 8) and the elbows are at the armrest in a position that does not conflict with the neighbour. A disadvantage might be privacy as the person positioned just a bit behind the other could watch the screen of the laptop or smartphone of their neighbour more easily than in the current situation. Also, the fact one of the four passengers will put the legs in the aisle could be an issue. Although some flight attendants mentioned that it happens now as well that passengers put their legs in the aisle. Some passengers also mentioned that the armrest and area under the armrest of the seat in front of the passenger contacting the knee could be redesigned to create space and the seat pan cushions should be softer for long haul flights. Next to the seat softness visitors also mentioned that the backrest angle should be more backwards or an addition of a recliner would be beneficial. However, the latter will introduce some extra eight, while the seats now are lighter than the current flying seats. 
Also, some visitors (experts in the field of aircraft interiors) mentioned that sitting with an angle of more than 18 degrees from the direction of flying needs additional measures as crashes will be worse for the human body. Extra measures could be needed like airbags. They pointed to literature on obliquely oriented seats (Humm et al., 2016). Some visitors also mentioned that booking for half of a flight and changing the seat is certainly appreciated. However, the practicality of the booking and changing needs further research. Another issue that was mentioned is evacuation. Having only exits on one side of the oval cabin might make the evacuation much harder. It still remains unknown to what extent, and how specifically, current regulations should fit this unconventional aircraft design.

\section{Discussion}

The first steps toward developing aircraft interior concepts that fit in the Flying V and could improve the passenger experience are made and it seems that all ideas get some support. Especially, the chaise longue is appreciated. However, a lot has to be studied further. In general, the evacuation needs further study, but also the booking and being seated more than 18 degrees off the direction of flying (according to studies like Humm et al. (2016) need further research. The latter might mean airbags for the sitting position in the bed, for the group space and chaise longue. Booking for half a flight might be an issue at a system level, as for instance the current booking systems don't have that option. But also in the daily practice of flying, attention is needed on how the passengers move and how to plan it in the flight schedule. For the specific four ideas, further research is needed.

Regarding the chaise longue, it is seen as promising by visitors as was mentioned before. Also, the use of the space in vertical direction to create more seat positions has been done before (e.g. http://jacobinnovations.com/FlexSeat.html and the Crystal Cabin Award winners 2019: Visionary Concepts ULTRAFLEX by AIM and the Boeing Company). So, many see this opportunity. However, in realizing it further steps still have to be made as all these concepts do not function yet and do not fly. Therefore, for the chaise longue, it is important to make a functional seat, with a mechanism to mount it to the fuselage, a working mechanism making the movement and then test it again with passengers.

In addition, the group space is not new. For instance, Rockwell made this set up for business jets (https://www.rockwellcollins.com/Products-andServices/Business-Aviation/Cabin-Interiors/Seating-Products/Executive-andVIP-Seating.aspx). Also, in trains it is often seen. However, in regular airliners this seat is not found yet. The safety certainly needs further study especially for the seat with the table in front of the passenger in the flight direction. Also, sitting in this position all the time in a long-haul flight might be too long and solutions are needed for that. Piro et al., (2019) showed that sitting opposite to each other is not the most comfortable position regarding communication. A 45or 90-degrees position is more desirable for communication. 
For the beds, duration might be an issue. Being in the bed 12 hours is seen as too long by the visitors. However, the flat bed is promising. Around $70 \%$ of the humans sleep on the side (Gordon, Grimmer, \& Trott, 2007) and this flatbed allows this position. Also, Torkashvand (2019) showed that among long haul flight passengers (95\% economy class) the lowest satisfaction was found for the activity 'sleeping', while sitting upright. This was affirmed by a survey among flight attendants in the same study. The mechanism for changing the beds to the seats for taxi, take-off and landing still has to be developed further. The interesting part of this development is that it might fit in current planes as well. Of course, going into the oval end of the cabin is not possible in traditional airplanes.

The staggered seats seem a good solution. It was appreciated and visitors preferred this over the current economy class seats on long haul flights, because of the leg space, not contacting the shoulder of the neighbour and not having to fight for the armrest. However some adaptations have to be made (e.g. cushion hardness, back rest inclination, the knee space at the arm rest in the seat in front of the passenger and it might be interesting to see if the 32" pitch can be reduced as leg space is now comparable to a 38 " pitch, which seems a lot. Anjani et al. (2019) showed that 34 " is already experienced as convenient. So, this should be studied further as well.

\section{Conclusion}

The hybrid interior of the flying $\mathrm{V}$ having a flat bed, staggered seats, a group space and a chaise longue, where different postures can be taken is appreciated by potential passengers. It is also clear that still much has to be studied further, like changing from one seat to the bed in the middle of the flight, evacuation and more detailed designs will be needed. The chaise longue seat certainly has potential as it is most preferred by the visitors.

\section{Acknowledgement}

The authors want to thank KLM for sponsoring and supporting the project. 


\section{References}

Ahmadpour, N., Robert, J. M., \& Lindgaard, G. (2014). A study of passengers' real-time emotional responses and comfort experience during the flight using the experience sampling method. AHFE International, 14, 194-202.

Anjani, S., Li, W., Vink, P., \& Ruiter, I. A. (2019). The effect of aircraft seat pitch on comfort, accepted for publication in Applied Ergonomics.

Atalık, Ö., Bakır. M., Akan, Ş. (2019). The role of ingress flight service quality on value for money in business class: A logit model on the airline industry. Administrative Sciences, 9(1), 26.

Bouwens. J., Tsay, W. J., \& Vink. P. (2017). The high and low comfort peaks in passengers' flight. Work, 258(4), 579-84.

Bouwens, J., Hiemstra-van Mastrigt, S., \& Vink, P. (2018). Ranking of human senses in relation to different ingress flight activities contributing to the comfort experience of airplane passengers. International Journal of Aviation, Aeronautics, and Aerospace, 5(2), Article 9.

Gordon, S. J., Grimmer, K. A., \& Trott, P. (2007). Sleep position, age, gender, sleep quality and waking cervico-thoracic symptoms. Internet Journal of Allied Health Sciences and Practice, 5(1), 6.

Hiemstra-van Mastrigt, S. (2015). Comfortable passenger seats: Recommendations for design and research (Unpublished doctoral dissertation). Delft University of Technology, Netherlands.

Homburg, B. A. (2017). Increasing passenger comfort during airside dwelltime (Unpublished master's thesis). Delft University of Technology, Netherlands.

Humm, J. R., Yoganandan, N., Pintar, F. A., Weese, R. L. de Moorcroft, D. M., Taylor, A. M., \& Peterson, B. (2016). Responses and injuries to PMHS in side-facing and oblique seats in horizontal longitudinal sled tests per FAA emergency landing conditions. SAE Technical Paper; 2016 Nov 7.

Kremser, F, Guenzkofer, F., Sedlmeier, C., Sabbah, O., \& Bengler, K. (2012). Aircraft seating comfort: the influence of seat pitch on passengers' well-being. Work, 1(41, Supplement 1), 4936-42.

Li, W., Chu, J., Gou, B., \& Wang, H. (2018). An investigation of key factors influencing aircraft comfort experience. In International Conference on Applied Human Factors and Ergonomics (pp. 222-232). Springer, Cham

Nijholt, N., Tuinhof, T., Bouwens, J. M., Schultheis, U., \& Vink, P. (2016). An estimation of the human head, neck and back contour in an aircraft seat. Work, 54(4), 913-23.

Piro, S., Fiorillo, I., Anjani, S., Smulders, M., Naddeo, A., \& Vink, P. (2019). Towards comfortable communication in future vehicles. Applied Ergonomics, 78, 210-16. 
Torkashvand, G. (2019). Optimization of cabin design for enhanced passenger experience (Unpublished doctoral dissertation). Florida Institute of Technology, Melbourne, FL.

Torkashvand, G, Stephane, L., \& Vink, P. (2019) Aircraft interior design and satisfaction for different activities; A new approach toward understanding passenger experience. International Journal of Aviation, Aeronautics, and Aerospace, 6(2), 5.

Vos, R., Geuskens, F. J. J. M. M., \& Hoogreef, M. F. M. (2012) A new structural design concept for blended wing body cabins. Proceedings of the 53rd AIAA/ASME/ASCE/AHS/ASC Structures, Structural Dynamics and Materials Conference.

Yao, X., \& Vink, P. (2019). A survey and a co-creation session to evaluate passenger contentment on long-haul flight, with suggestions for possible design improvements to future aircraft interiors. Proceedings of the International Comfort Congress. 